\title{
Validity of mortality data for Parkinson's disease
}

\author{
N J Phillips, J Reay, C N Martyn
}

Although mortality data have been used to examine both the time trends and the geographical distribution of Parkinson's disease, ${ }^{12}$ there are no recent investigations of the validity of such data in the United Kingdom. Studies carried out in the United States of America and elsewhere suggest that there might be a considerable degree of under-reporting of this diagnosis on death certificates. ${ }^{34}$ We investigated how fully Parkinson's disease was recorded on death certificates among cases in one area of England between 1966 and 1997.

\section{Methods}

Ward admission books and outpatient registers from the Wessex Neurological Centre, Southampton, UK were searched to identify patients with a possible diagnosis of Parkinson's disease between 1965 and 1990. Their case records were examined and patients with drug induced Parkinsonism or Parkinsonian syndromes other than idiopathic Parkinson's disease were excluded. We identified 238 people who had been seen by a consultant neurologist and given a final clinical diagnosis of idiopathic Parkinson's disease. The Office for National Statistics was able to trace $219(92 \%)$ of the subjects: 171 $(72 \%)$ had died; $42(18 \%)$ were still alive; four were not currently registered with a general practitioner and two had emigrated. We examined copies of the death certificates of those who had died using logistic regression to explore factors that might influence the recording of Parkinson's disease.

\section{Results}

Parkinson's disease was recorded in either part I or part II of the death certificates of 130 $(76 \%)$ of the 171 people (108 men and 63 women) who had died. Their deaths occurred between 1966 and 1997. Logistic regression analysis showed no evidence that the likelihood of Parkinson's disease being mentioned on the death certificate had changed during this period (see fig 1) or that it differed between the sexes or that it varied with age at death. In 63 (37\%) people, Parkinson's disease (International Classification of Disease 9th revision 332.0) was coded as the underlying cause of death. During the period of study, there were changes in the way the Office of Population Censuses and Surveys (now the Office for National Statistics) implemented WHO rule 3, which governs how the underlying cause of death is selected from the conditions listed in both parts of the death certificate. Between 1984 and 1992, the way in which this rule was interpreted resulted in a decrease in mortality from certain causes such as pneumonia, while deaths from causes mentioned in part II increased. ${ }^{5}$ Among the people in this study, those dying between 1984 and 1992 were more than twice as likely to have Parkinson's disease coded as the underlying cause of death (odds
MRC Environmental Epidemiology Unit, University of Southampton, Southampton General Hospital, Southampton SO16 6YD

Correspondence to: Dr C N Martyn.

Accepted for publication 13 April 1999

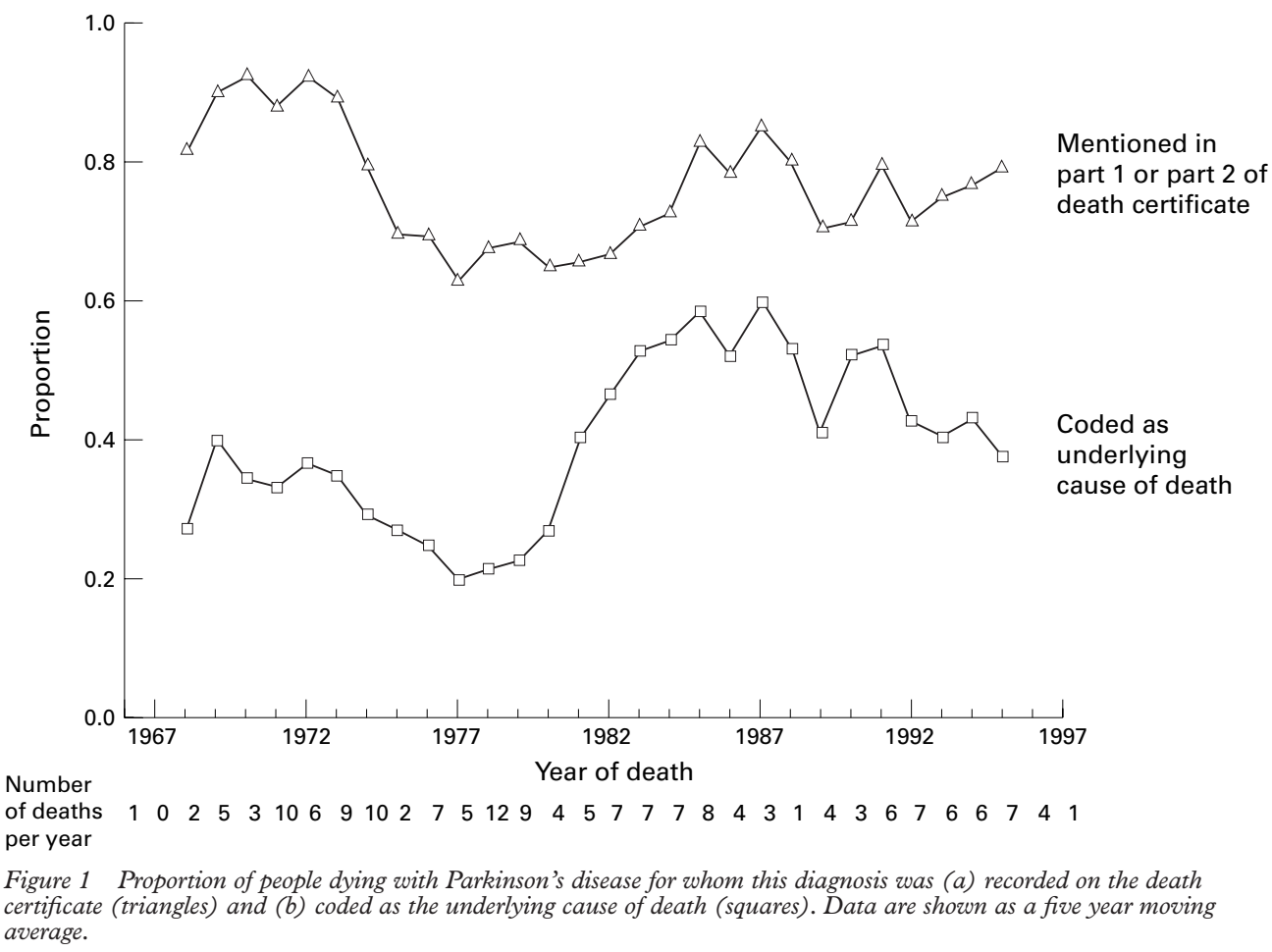


ratio $=2.53,95 \%$ CI 1.25 to 5.13$)$. After taking account of the effects of the changes in WHO rule 3, either using the conversion factor suggested by OPCS or by including a term for this period in the logistic regression analysis, there were no statistically significant differences over time in the likelihood of Parkinson's disease being coded as the underlying cause of death (see fig 1).

\section{Discussion}

In this group of patients, all diagnosed during life as having idiopathic Parkinson's disease, only $37 \%$ had Parkinson's disease coded as the underlying cause of death. During the period 1984 to 1992 , a change in the interpretation of WHO rule 3 resulted in a twofold increase in the likelihood of Parkinson's disease being coded as the underlying cause of death. Apart from this the data do not suggest that there have been substantial changes over the past three decades either in the probability of Parkinson's disease being recorded by the doctor certifying death or in the likelihood that it is coded as the underlying cause. However, the study is too small to interpret time trends with great confidence.

The only other recent study of death certification in Parkinson's disease, in Ohio, USA, also found a similar degree of under-reporting but whether these findings apply to other populations is unknown.

We are grateful to the Office for National Statistics for tracing the subjects and providing us with their death certificates and to P D Winter and A W Shiell for help with computing and statistical advice.

Funding: the study was funded by the Parkinson's Disease Society.

1 Kurtzke JF, Murphy MM. The changing patterns of death rates in Parkinsonism. Neurology 1990;40:42-9.

2 Smith WCS, Mutch WJ. Time trends and geographical variation in Parkinson's disease in Scotland. Scott Med $\mathcal{f} 1992$;
at ation in Par:

3 Paulson GW, Gill WM. Are death certificates reliable to estimate the incidence of Parkinson's disease? Mov Disord 1995;10:678.

4 Kessler II. Parkinson's disease in epidemiologic perspective. Adv Neurol 1978:19:355-84.

5 Office of Population Censuses and Surveys. Mortality statistics (cause), 1974-84, England and Wales. Series DH2 No.111. London: HMSO, 1975-85. 